\title{
Mechanically driven phase separation and corresponding microhardness change in Cu60Zr20Ti20 bulk metallic glass
}

\author{
Cao, Q.P.; Li, J.F.; Zhou, Y.H.; Jiang, Jianzhong
}

Published in:

Applied Physics Letters

Link to article, DOI:

$10.1063 / 1.1862329$

Publication date:

2005

Document Version

Publisher's PDF, also known as Version of record

Link back to DTU Orbit

Citation (APA):

Cao, Q. P., Li, J. F., Zhou, Y. H., \& Jiang, J. (2005). Mechanically driven phase separation and corresponding microhardness change in Cu60Zr20Ti20 bulk metallic glass. Applied Physics Letters, 86(8), 081913.

https://doi.org/10.1063/1.1862329

\section{General rights}

Copyright and moral rights for the publications made accessible in the public portal are retained by the authors and/or other copyright owners and it is a condition of accessing publications that users recognise and abide by the legal requirements associated with these rights.

- Users may download and print one copy of any publication from the public portal for the purpose of private study or research.

- You may not further distribute the material or use it for any profit-making activity or commercial gain

- You may freely distribute the URL identifying the publication in the public portal 


\title{
Mechanically driven phase separation and corresponding microhardness change in $\mathrm{Cu}_{60} \mathrm{Zr}_{20} \mathrm{Ti}_{20}$ bulk metallic glass
}

\author{
Qingping Cao, Jinfi Li, ${ }^{a}$ and Yaohe Zhou \\ State Key Laboratory of Metal Matrix Composites, School of Materials Science and Engineering, \\ Shanghai Jiao Tong University, Shanghai 200030, People's Republic of China \\ Jianzhong Jiang \\ Department of Materials Science and Engineering, Zhejiang University, Hangzhou 310027, \\ People's Republic of China and Department of Physics, Building 307, Technical University of Denmark, \\ DK-2800 Lyngby, Denmark
}

(Received 27 May 2004; accepted 13 December 2004; published online 16 February 2005)

\begin{abstract}
Rolling deformation of bulk $\mathrm{Cu}_{60} \mathrm{Zr}_{20} \mathrm{Ti}_{20}$ metallic glass has been performed at cryogenic temperature. The specimens exhibit excellent ductility, and are rolled up to $97 \%$ reduction in thickness without fracture. Crystallization is suppressed during the deformation, however, phase separation is observed in the glassy matrix when the thickness reduction exceeds $89 \%$. Once the phase separation occurs, the microhardness of the specimen increases drastically, indicating the existence of work hardening by severe plastic deformation of the metallic glass. () 2005 American Institute of Physics. [DOI: 10.1063/1.1862329]
\end{abstract}

Compared with polycrystalline alloys, metallic glasses exhibit very high yield strength, but their fracture at temperatures far below the glass transition, under uniaxial tension, generally occurs along a narrow shear band with little global plasticity. ${ }^{1}$ Such a catastrophic fracture extremely limits the application of metallic glasses as structural materials, and is attributed by many researchers to the lack of work hardening in metallic glasses under plastic deformation. ${ }^{2,3}$ However, microstructure examinations have revealed the existence of crystalline phases in the shear bands, ${ }^{4-7}$ indicating that the fracture progress is accompanied by a partial crystallization, and the effect of crystallization on the fracture cannot be excluded. In order to understand how metallic glasses change their mechanical properties when they are subjected to severe plastic deformation and do not crystallize, further investigation is needed.

Using high critical cooling rates, conventional metallic glasses can be produced by rapid quenching into thin ribbons, filaments, or foils, and obviously are not suitable for the severe plastic deformation experiment. Recently, the discovery of bulk metallic glasses (BMGs), ${ }^{8}$ changes the situation. Ternary $\mathrm{Cu}_{60} \mathrm{Zr}_{20} \mathrm{Ti}_{20}$ alloy was chosen as the experimental material mainly because of its good ductility in the glassy state. ${ }^{9}$ Glassy rods of $2 \mathrm{~mm}$ in diameter were produced by copper mold casting. The detailed preparation procedure was described elsewhere. ${ }^{10}$ The rods were cut into short cylinders with a thickness of $1.5 \mathrm{~mm}$ for rolling. The rolling apparatus consisted of two $100 \mathrm{~mm}$ diameter rollers. Covered by two steel plates with $1 \mathrm{~mm}$ original thickness, the specimen was repeatedly rolled in one direction until the desired deformation was obtained. The degree of deformation was denoted by the reduction in thickness $\varepsilon=$ $\left(h_{0}-h\right) / h_{0}$, where $h_{0}$ and $h$ represented the specimen thicknesses before and after rolling, respectively. Many small deformation passes were used with a progressively narrowing gap between the two rollers. The decrease of the gap during

${ }^{\text {a) }}$ Author to whom all correspondence should be addressed; electronic mail: jfli@sjtu.edu.cn the deformation was carefully controlled so that the strain rate was in the range of $1.0 \times 10^{-2}-1.0 \times 10^{-3} \mathrm{~s}^{-1}$. In order to suppress crystallization, a continuous liquid nitrogen stream was used to cool the specimen throughout the rolling operation, and the temperature of the specimen was measured to be about $150 \mathrm{~K}$.

The microstructures of the specimens subjected to different degrees of deformation were examined by highresolution transmission electron microscope (HRTEM) with an accelerating voltage of $300 \mathrm{kV}$ (JEOL JEM-3000F) and x-ray diffractometer (XRD) with monochromatic $\mathrm{Cu} K_{\alpha}$ radiation. HRTEM specimens were prepared by low-energy ion milling at $2.5 \mathrm{kV}$ and $5 \mathrm{~mA}$ with liquid nitrogen cooling. The selected area electron diffraction (SAED) pattern was taken from an area about $0.1 \mu \mathrm{m}$ in diameter. Local chemical composition was determined by energy dispersive $\mathrm{x}$-ray (EDX) analysis. Thermal analyses were performed in a Pyris Diamond differential scanning calorimeter (DSC) at 20 $\mathrm{K} / \mathrm{min}$ under a flow of purified argon. The microhardness of the specimens was measured by a Leitz Durimet Vickers hardness tester, which consisted of a square-based pyramidal diamond indenter with a $136^{\circ}$ angle between opposite faces of the indenter. The static load was $200 \mathrm{~g}$ and the dwell time of loading was $15 \mathrm{~s}$. Twenty indentations were made on each specimen.

Thickness reduction as high as $97 \%$ was achieved in the rolling deformation. The specimen with such a deformation degree had no cracks, and remained ductile, as shown by the $180^{\circ}$ bending without fracture. No crystalline phases were detected by XRD in all the as-cast and as-rolled $\mathrm{Cu}_{60} \mathrm{Zr}_{20} \mathrm{Ti}_{20}$ specimens. Figure 1 shows their XRD patterns. By fitting the broad diffraction peak located at $2 \theta \approx 41^{\circ}$ using either of the Gauss and Lorentz line profiles, it is clear that the full width at half maximum (FWHM) increases by about $9 \%$ from the as-cast to the as-rolled specimen with $\varepsilon=89 \%$ and then decreases by about $3 \%$ from $\varepsilon=89 \%$ to $\varepsilon=97 \%$ (Fig. 2).

Measurement of the microhardness $H_{v}$ of the specimens shows that its variation with $\varepsilon$ can be divided into two stages: A slow increase from the as-cast value 5.89 to 5.99 


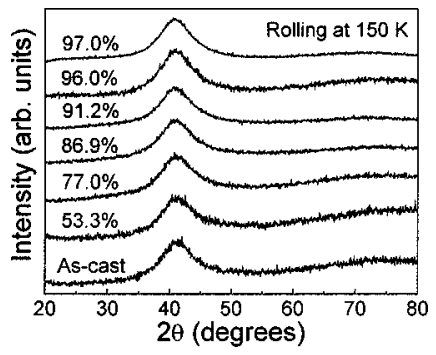

FIG. 1. XRD patterns recorded for the as-cast and as-rolled $\mathrm{Cu}_{60} \mathrm{Zr}_{20} \mathrm{Ti}_{20}$ specimens with different $\varepsilon$.

GPa for $\varepsilon=89 \%$ and a rapid increase up to $6.33 \mathrm{GPa}$ from $\varepsilon=89 \%$ to $\varepsilon=97 \%$ (Fig. 2). In the present work, the ratio of the specimen thickness to the corresponding indentation depth at different $\varepsilon$ is in the range of 13 to 423 . It constantly satisfies the requirement that the ratio should be larger than $10,{ }^{11}$ indicating that the microhardness measurement is reliable. To further confirm this argument, we rolled another three specimens with $h_{0}=2 \mathrm{~mm}$ to different thickness reduction values $91 \%, 96 \%$, and $97 \%$, respectively. Their microhardness values are also shown in Fig. 2. Indeed, there is no obvious difference between the two sets of data.

The crystallization of $\mathrm{Cu}_{60} \mathrm{Zr}_{20} \mathrm{Ti}_{20}$ BMG during annealing proceeds through two separate exothermic reactions. ${ }^{12,13}$ DSC measurements of the as-rolled specimens with different $\varepsilon$ indicate that the areas of the both exothermic peaks are almost unchanged compared to the as-cast specimen (not shown here). So, the possibility of crystallization in the asrolled specimens can be excluded. This conclusion is also supported by the following TEM observation.

It is well known that the deformation of metallic glasses at high stresses and low temperatures is inhomogeneous. ${ }^{14}$ The deformation is virtually confined to the narrow regions near the shear bands. ${ }^{15}$ These regions, therefore, are more favorable for deformation-induced microstructural changes than the regions far away from the shear bands. Figure 3(a) shows the bright-field image of the as-rolled specimen with $\varepsilon=89 \%$. Similar to the TEM images of other as-rolled specimens for $\varepsilon<89 \%$, no strong contrast was observed except for the increase in the density of the shear bands. The inset in Fig. 3(a) is a SAED pattern taken from the area between two shear bands, and it consists of a broad diffraction halo and a faint larger one, which are typical for amorphous materials. As $\varepsilon$ is larger than $89 \%$, some gray regions near the shear bands begin to appear in the microstructure and their number and size increase with $\varepsilon$. The TEM image of the specimen deformed by $\varepsilon=97 \%$ is shown in Fig. 3(b), where the sizes of the gray regions are in the range of $100-120 \mathrm{~nm}$. The

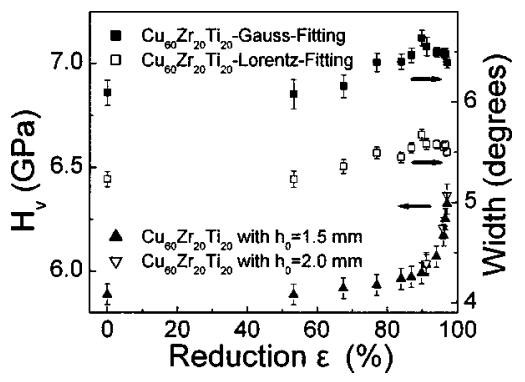

FIG. 2. Microhardness and FWHM of XRD patterns of $\mathrm{Cu}_{60} \mathrm{Zr}_{20} \mathrm{Ti}_{20}$ specimens as a function of $\varepsilon$, respectively. HRTEM images of the selected areas in Fig. 3(c), respec-
mens as a function of $\varepsilon$, respectively.
Downloaded 07 Jun 2010 to 192.38.67.112. Redistribution subject to AlP license or copyright; see http://apl.aip.org/api/copyright.jsp

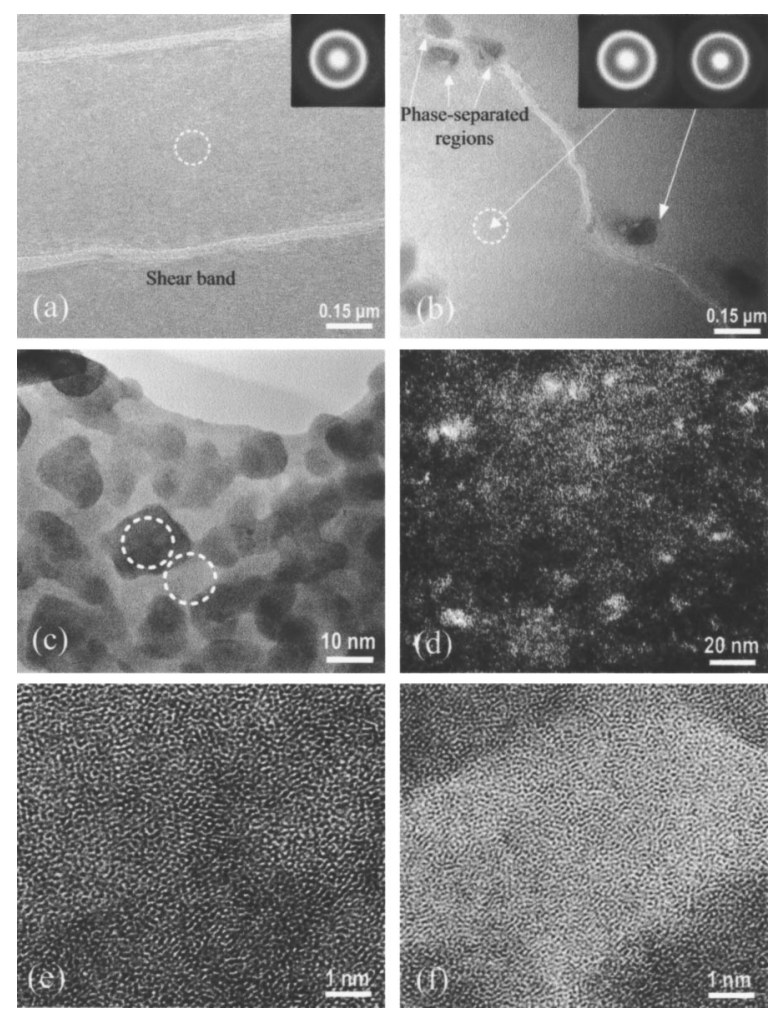

FIG. 3. (a) TEM bright-field image of the as-rolled specimen with $\varepsilon$ $=89 \%$. The inset is the SAED pattern taken from the area marked by a dotted-line circle. (b) TEM bright-field image of the as-rolled specimen with $\varepsilon=97 \%$. The insets are the SAED patterns of the amorphous matrix marked by a dotted-line circle and the gray phase-separated region. (c) High magnification TEM bright-field image of the phase-separated region of the asrolled specimen with $\varepsilon=97 \%$, (d) TEM dark-field image of the phaseseparated region of the as-rolled specimen with $\varepsilon=97 \%$, (e) and (f) HRTEM images of the selected areas marked by the dotted-line circles in (c).

SAED patterns obtained from the gray region and the amorphous matrix are the insets in Fig. 3(b), where only diffraction haloes are observed. Chemical compositions of the gray regions and of the amorphous matrix were estimated by EDX with a beam size of about $0.1 \mu \mathrm{m}$. The results show that the average composition in the gray regions is 64 at. $\% \mathrm{Cu}, 17$ at. $\% \mathrm{Ti}$, and 19 at. $\% \mathrm{Zr}$, while the amorphous matrix contains 57 at. $\% \mathrm{Cu}, 22$ at. $\% \mathrm{Ti}$, and 21 at. \% Zr. Note that chemical composition of the gray regions is distinct from the stoichiometric ratio of the primary $\mathrm{Cu}_{51} \mathrm{Zr}_{14}$ phase in the crystallization of $\mathrm{Cu}_{60} \mathrm{Zr}_{20} \mathrm{Ti}_{20}$ BMG. ${ }^{16}$

It must be pointed out that the gray regions are uneven in structure at higher magnification. Such a transmission electron microscopy (TEM) image of the specimen with $\varepsilon$ $=97 \%$ is shown in Fig. 3(c), where the microstructure consists of the brighter matrix and the darker substructures with an average size about $10-20 \mathrm{~nm}$. Their chemical compositions were estimated by nanobeam EDX with a beam size of about $3 \mathrm{~nm}$. The results show that the average composition in the darker substructures is 70 at. $\% \mathrm{Cu}, 13$ at. \% Ti, and 17 at. $\% \mathrm{Zr}$, while the brighter matrix contains 54 at. $\% \mathrm{Cu}, 21$ at. $\% \mathrm{Ti}$, and 25 at. $\% \mathrm{Zr}$. Such a chemical inhomogeneity is also revealed by the dark-field image, as shown in Fig. 3(d), where the bright and dark speckles are clearly visible. The bright speckles in the dark-field image were found in the TEM observation corresponding to the darker substructure, i.e., they are rich in copper. Figures 3(e) and 3(f) show the 
tively. No lattice fringes are observed in the darker substructure and the brighter matrix. Hence, it is clear that mechanically driven phase separation, rather than crystallization, occurs in the as-rolled specimens when $\varepsilon$ exceeds $89 \%$.

When a metal is cold deformed, part of the mechanical energy is stored in the form of defects. ${ }^{17}$ For metallic glasses, the consequence is the increase of the free volume. ${ }^{14,18,19}$ Three processes determine the free volume content during deformation: Diffusion, annihilation, and generation. ${ }^{20}$ Considering that the diameter of the rollers in the experiment is evidently larger than the thickness of the as-cast specimen, and the thickness reduction in each rolling pass is very small, the deformation of the specimen is thought to take place mainly under the compressive stress. ${ }^{21}$ In this case, the eventual free volume content in the as-rolled specimens is mainly dependent on the strain. Before the saturated free volume content is reached, the generation rate of free volume during the deformation is always greater than the annihilation rate, and as a result the free volume content increases with $\varepsilon^{22}$ Accordingly, the FWHM of the amorphous peak increases with $\varepsilon$ due to the increased disorder of the metallic glass. ${ }^{23}$ At this stage, we do not know whether the saturated free volume content has been achieved in the as-rolled specimen with $\varepsilon=89 \%$, since after then phase separation occurs and the FWHM of the amorphous peak decreases owing to other reasons.

If the short-range order did not change when the phase separation occurred, the broadening of the amorphous diffraction peaks in XRD and the haloes in SAED would be expected. But the fact is that the diffraction peaks and haloes become narrower as the phase separation develops. This can be ascribed to the enhancement of the short-range order in the phase-separation amorphous alloy. The reduction in the width of the diffraction peak was observed by Pekarskaya $e t$ $a l^{24}$ in the splat-cooled $\mathrm{Zr}_{52.5} \mathrm{Ti}_{5} \mathrm{Cu}_{17.9} \mathrm{Ni}_{14.6} \mathrm{Al}_{10}$ glass when the phase separation occurred during annealing. Comparing the insets of Figs. 3(a) and 3(b), it is known that the distinction in the diffraction haloes between the amorphous alloy without phase separation and the matrix of the phaseseparated amorphous alloy is not obvious, while the width of the first diffraction halo from the gray phase-separated region decreases significantly. Therefore, the phase-separated regions exhibit more order in structure than the amorphous matrix although both maintain the amorphous state. It is the enhancement of the short-range order in the phase-separated regions that makes the FWHM decrease when $\varepsilon$ is larger than $89 \%$.

Although no phase separation is observed in the asrolled specimens by TEM for $\varepsilon \leqslant 89 \%$, it is believed that the microinhomogeneity of chemical composition can be enhanced by the plastic deformation, which brings about the slight rise of the microhardness in the $\varepsilon$ range from 0 to $89 \%$. When $\varepsilon$ exceeds $89 \%$, phase separation develops rapidly, and the microhardness increases drastically. The strengthening mechanism induced by phase separation in $\mathrm{Cu}_{60} \mathrm{Zr}_{20} \mathrm{Ti}_{20}$
BMG remains a puzzle at present. It may be correlated with: (i) The hardnesses of the separated glassy phases and (ii) the volume fraction and size of the precipitated glassy phase. Further investigation is needed.

In summary, bulk $\mathrm{Cu}_{60} \mathrm{Zr}_{20} \mathrm{Ti}_{20}$ metallic glass has been rolled up to $\varepsilon=97 \%$ without cracks, and crystallization was suppressed by using liquid nitrogen cooling. Such a high degree of deformation without crystallization was seldom reached, and it is revealed that phase separation can be triggered by severe plastic deformation and the phase-separated regions have enhanced short-range order compared with the amorphous matrix. Furthermore, this mechanically driven phase separation can lead to a drastic increase of the microhardness of the metallic glass. Such a phenomenon clearly suggests that work hardening may occur in the plastic deformation of metallic glasses without crystallization.

Financial support from the National Natural Science Foundation of China under Grant No. 50171043 and the DANIDA Fellowship Centre are gratefully acknowledged.

${ }^{1}$ H. J. Leamy, H. S. Chen, and T. T. Wang, Metall. Trans. 3, 699 (1972).

${ }^{2}$ C. T. Liu, L. Heatherly, D. S. Easton, C. A. Carmichael, J. H. Schneibel, C. H. Chen, J. L. Wright, M. H. Yoo, J. A. Horton, and A. Inoue, Metall. Mater. Trans. A 29, 1811 (1998).

${ }^{3}$ H. A. Bruck, A. J. Rosakis, and W. L. Johnson, J. Mater. Res. 11, 503 (1996).

${ }^{4}$ H. Chen, Y. He, G. J. Shiflet, and S. J. Poon, Nature (London) 367, 541 (1994).

${ }^{5}$ M. L. Trudeau, Appl. Phys. Lett. 64, 3661 (1994).

${ }^{6}$ J. Xu and M. Atzmon, Appl. Phys. Lett. 73, 1085 (1998).

${ }^{7}$ W. H. Jiang and M. Atzmon, Acta Mater. 51, 4095 (2003).

${ }^{8}$ W. L. Johnson, MRS Bull. 24, 42 (1999).

${ }^{9}$ A. Inoue, W. Zhang, T. Zhang, and K. Kurosaka, Mater. Trans., JIM 42, 1149 (2001).

${ }^{10}$ Q. P. Cao, Y. H. Zhou, A. Horsewell, and J. Z. Jiang, J. Phys.: Condens. Matter 15, 8703 (2003).

${ }^{11}$ H. M. Pollock, D. Maugis, and M. Barquins, in Microindentation Techniques in Materials Science and Engineering, American Society for Testing and Materials Special Technical Publication No. 889, edited by P. J. Blau and B. R. Lawn (ASTM, Philadelphia, PA, 1986), p. 47.

${ }^{12}$ A. Concustell, Á. Révész, S. Suriñach, M. D. Baró, L. K. Varga, and G. Heunen, J. Mater. Res. 19, 505 (2004).

${ }^{13}$ J. Z. Jiang, B. Yang, K. Saksl, H. Franz, and N. Pryds, J. Mater. Res. 18, 895 (2003).

${ }^{14}$ F. Spaepen, Acta Metall. 25, 407 (1977).

${ }^{15}$ J. C. Lee, Y. C. Kim, J. P Ahn, H. S Kim, S. H. Lee, and B. J. Lee, Acta Mater. 52, 1525 (2004).

${ }^{16}$ J. Z. Jiang, J. Saida, H. Kato, T. Ohsuna, and A. Inoue, Appl. Phys. Lett. 82, 4041 (2003)

${ }^{17}$ Y. M. Wang, M. W. Chen, H. W. Sheng, and E. Ma, J. Mater. Res. 17, 3004 (2002)

${ }^{18}$ A. S. Argon, Acta Metall. 27, 47 (1979).

${ }^{19}$ P. S. Steif, F. Spaepen, and J. W. Hutchinson, Acta Metall. 30, 447 (1982).

${ }^{20}$ R. Huang, Z. Suo, J. H. Prevost, and W. D. Nix, J. Mech. Phys. Solids 50, 1011 (2002).

${ }^{21}$ M. D. Stone, Iron Steel Eng. 30, 61 (1953).

${ }^{22}$ K. M. Flores and R. H. Dauskardt, Acta Mater. 49, 2527 (2001).

${ }^{23}$ T. Masumoto and R. Maddin, Mater. Sci. Eng. 19, 1 (1975).

${ }^{24}$ E. Pekarskaya, J. F. Löffler, and W. L. Johnson, Acta Mater. 51, 4045 (2003). 